\section{Emergency Cardiovascular Pharmacotherapy: A Point-of-Care Guide}

Wiggins BS, Sanoski CA. American Society of Health-System Pharmacists, Bethesda, Maryland, 2012. ISBN 978-1-58528-256-2. Softcover, 236 pages. US\$35 for ASHP members (US\$39 for nonmembers).

Sudden cardiac arrest is associated with a high mortality rate. Optimization of outcomes in individuals affected by this condition requires quick and decisive action. Emergency Cardiovascular Pharmacotherapy is intended as a pocket guide for pharmacists who encounter these patients in their practices. Its intent is to provide a quick, all-in-one guide for therapy in cardiovascular emergencies.

This guide covers multiple topics, each written by a different expert in the field from throughout the United States. In total, there are 10 chapters. The first 3 chapters explore the concept of advanced cardiac life support (ACLS) and its origins, basic skills for interpreting electrocardiograms, and the principles of emergency drug administration in patients with poor perfusion and in situations where there is no IV access. The next 3 chapters cover 3 types of medications: antiarrhythmics, vasoactive and inotropic agents, and fibrinolytics, respectively. For each drug, the specific pharmacokinetic and pharmacodynamic parameters, dosing, and the medication's place in therapy are discussed. The final 4 chapters of this guide cover management principles for electrolyte abnormalities, therapeutic hypothermia, arrhythmias, and toxicology, respectively.

This guide draws from the existing evidence base and uses recommendations from the American Heart Association Guidelines for Cardiopulmonary Resuscitation and Emergency Cardiovascular Care. ${ }^{1}$ The pharmacist-specific perspective helps the reader to understand the role of the pharmacist on a code team, as well as outlining the parameters of each medical therapy specific to an emergency situation. The clinical pearls that are incorporated into each chapter represent beneficial therapeutic tips for each therapy. As a teaching tool, the case studies at the end of each chapter reinforce the points outlined and help to clarify any confusion. This book contains various charts with dosing information, algorithms, and pharmacokinetic parameters, which can be used as quick reference tools in daily practice.

Although this book will be a useful tool for developing an understanding of emergency cardiovascular pharmacotherapy, it has several limitations. The book was written from the US perspective and, as such, discusses medications that are available only in the United States, while neglecting those available only in Canada. Units of measure are presented in conventional US units, which must be converted to SI units to be useful in Canadian practice. Additionally, while the first 3 chapters explore important concepts in the emergent management of cardiovascular emergencies, they add bulk to the book, limiting its practicality as a pocket guide.

This book could be of great use to those seeking an introduction to or refresher on the management of emergency cardiovascular situations. It contains concise, accurate information on various principles of emergency drug therapy, as well as management principles for several important pathological conditions. The comprehensive index will help in urgent scenarios where a quick reference is required. However, in this technological age, an electronic format would greatly increase the ease of information retrieval, improve the book's "pocketability", and provide a more up-to-date resource.

\section{References}

1. Field JM, Hazinski MF, Sayre MR, Chameides L, Schexnayder SM, Hemphill R, et al. Part 1: executive summary: 2010 American Heart Association guidelines for cardiopulmonary resuscitation and emergency cardiovascular care. Circulation 2010;122(18 Suppl 3):S640-S656.

Angus Kinkade, PharmD, BCPS

Clinical Pharmacy Specialist-Emergency Medicine

St Paul's Hospital

Vancouver, British Columbia 